\title{
OS DIREITOS FUNDAMENTAIS NAS MODERNAS CONSTITUIÇÕES: ANÁLISE COMPARATIVA ENTRE AS CONSTITUIÇÕES ALEMÃ, NORTE-AMERICANA E BRASILEIRA $^{1}$
}

\author{
Winfried Brugger ${ }^{2}$ \\ Mônia Clarissa Hennig Leaß
}

\section{RESUMO}

Este artigo pretende estabelecer uma reflexão acerca de alguns dos aspectos destacados e importantes da evolução do constitucionalismo moderno, analisando a posição legal e o impacto dos direitos humanos e fundamentais na estrutura das Constituições modernas, a partir de um quadro esquemático inspirado na teoria dos status fundada por Jellinek. Nesse sentido, percebe-se que os direitos fundamentais desempenham um papel estratégico de garantia e de consolidação dessas conquistas, podendo-se perceber elementos comuns entre a Lei Fundamental alemã e a Constituição brasileira de 1988.

Palavras-chave: Constitucionalismo moderno. Constituição brasileira de 1988. Direitos Fundamentais. Lei Fundamental alemã. Teoria dos status de Jellinek.

\section{INTRODUÇÃO - finalidade e estrutura das Constituições modernas}

Este artigo pretende estabelecer uma reflexão acerca de alguns dos aspectos destacados e importantes do constitucionalismo moderno, analisando a posição legal e o impacto dos direitos humanos e fundamentais na estrutura das Constituições modernas. Para tanto, desenvolve-se, notadamente a partir de um quadro esquemático inspirado na teoria dos status fundada por Jellinek, um panorama evolutivo do próprio constitucionalismo e das conquistas por ele incorporadas ao longo do tempo, desde a conformação e vinculação da questão da soberania e da limitação do poder até a necessidade de se pensar a realidade constitucional em um mundo globalizado. Nesse sentido, percebe-se que os direitos fundamentais - cujas gerações ou dimensões podem ser associadas a cada um dos status propostos - desempenham um papel estratégico de garantia e de 
consolidação dessas conquistas, podendo-se perceber elementos comuns - aqui analisados em face da Constituição brasileira de 1988 - ensejadores do que se poderia chamar de uma "teoria geral do constitucionalismo ocidental".

\section{SOBERANIA}

Para que se possa entender a importância e a função desempenhada pelos direitos fundamentais constitucionais, é necessário que se visualize como eles se relacionam com a soberania de um Estado. O Brasil, por exemplo, se intitula como um "Estado soberano" (art. 10, inciso I, da Constituição). A soberania, em geral, compreende o poder de legislar, de aplicar a lei e de adjudicar as disputas com relação a determinadas pessoas dentro de um determinado território. ${ }^{4}$ Surge, então, a questão: este poder de regulação e de governo é limitado ou ilimitado? No momento em que o termo soberania estatal se tornou proeminente, nos séculos XVI e XVII, quando as guerras civis e religiosas estavam afetando diversos locais da Europa, a soberania foi vista como um poder essencialmente ilimitado de regular a vida das pessoas e, se necessário, para pacificar o povo por meio da força, no intuito de se assegurarem a vida e a paz para todos. Assim, a noção de soberania ilimitada não foi idealizada no sentido de permitir ou dar ao governo o direito de fazer o que bem entendesse (como, por exemplo, explorar ou discriminar seu povo). Ela foi, isto sim, pensada para assegurar a todos, em tempos de crise, a paz. O principal argumento, para tanto, utilizado durante os vários séculos em que se viveu sob a noção de soberania como um poder ilimitado, foi e é o de que, em uma situação de anarquia ou de guerra, é necessário que se imponha a força para se assegurar a paz. Mas, uma vez alcançada a paz, reconhecer ou atribuir a qualquer governo um poder irrestrito traz um novo risco: o da tirania. Nesse sentido, pode-se dizer que as Constituições modernas foram inventadas e tiveram êxito exatamente porque elas transformaram a soberania irrestrita de um governo sem limites em uma soberania e um poder limitados, visando a garantir uma vida pacífica e segura para cada cidadão que vive naquele Estado.

É possível perceber, com relação a esta questão, que a Constituição brasileira reconhece e incorpora esta transformação da noção de soberania de irrestrita para 
limitada, o que resta evidente já no texto do art. $1^{\circ}$, inciso $\mathrm{I}$, do texto constitucional: lá, antes de caracterizar a República Federativa do Brasil como um Estado soberano, o referido artigo vincula os poderes constituídos - Legislativo, Executivo e Judiciário - à democracia, à cidadania, à dignidade e à pluralidade, para, somente então, estabelecer a separação de poderes (art. $2^{\circ}$ ). Assim, tem-se que o quadro é claro: a Constituição estabelece um governo com poderes limitados, estando esta limitação baseada em quatro instrumentos, descritos abaixo.

1) A Constituiçãa reina suprema (supremacia da Constituição). É a Constituição que organiza e determina quem pode - ou não pode - fazer o quê e como os órgãos estatais devem proceder. Além disso, a própria Constituição ainda institui outras três estratégias de limitação do poder, que são nominadas na seqüência.

2) Separação - vertical - dos poderes (sistema federativo), por meio do estabelecimento de poderes nacionais, estaduais e municipais que concorrem entre si, estando, ainda, na via inversa, igualmente vinculados ao Direito Internacional.

3) Separação - horizontal - dos poderes (sistema de freios e contrapesos). Legislativo, Executivo e Judiciário possuem autonomia, tendo esta relação a Corte Constitucional como árbitro final. ${ }^{5}$

4) Direitos fundamentais e humanos como limites à atuação do poder estatal em face dos indivíduos.

Todos estes mecanismos de limitação e de vinculação do governo servem, por fim, a um único propósito: assegurar uma justa representação de cada pessoa e grupo na política (nível interno) e permitir que o Brasil tenha um espaço produtivo de inserção na comunidade internacional.

A Constituição brasileira é, portanto, um excelente exemplo de integração entre os estágios de evolução e de transformação dos Estados-Nação nos últimos quatro ou cinco séculos, conforme se pode depreender da análise do quadro esquemático desenvolvido com base na "teoria dos status" de Jellinek, que constitui uma importante parte de sua clássica obra System der subjektiven öffentlichen Rechte. ${ }^{6}$ 
O quadro a seguir apresentado foi, todavia, atualizado ${ }^{7}$, levando-se em consideração, notadamente, os estágios 5 e 6.

3 EVOLUÇÃO DAS CONSTITUIÇÕES MODERNAS E O PAPEL DOS DIREITOS HUMANOS (de acordo com a "teoria dos status" de Jellinek)

\begin{tabular}{|c|c|c|c|}
\hline $\begin{array}{l}\text { Relação entre Estado } \\
\text { e indivíduo }\end{array}$ & $\begin{array}{l}\text { Problema a ser } \\
\text { resolvido }\end{array}$ & Solução do problema & $\begin{array}{l}\text { Proeminentemente } \\
\text { analisado por }\end{array}$ \\
\hline $\begin{array}{l}\text { 1 Soberania: } \\
\text { indivíduo sujeito ao } \\
\text { poder pleno do } \\
\text { governo. "Status } \\
\text { subjectionis". }\end{array}$ & $\begin{array}{l}\text { Anarquia, guerra, } \\
\text { ruptura do poder } \\
\text { político ou religioso. }\end{array}$ & $\begin{array}{l}\text { Unidade nacional, } \\
\text { poderes absolutos } \\
\text { sobre o povo e sobre o } \\
\text { território. }\end{array}$ & $\begin{array}{l}\text { Jean Bodin } \\
\text { Thomas Hobbes }\end{array}$ \\
\hline $\begin{array}{l}2 \text { Liberdade: } \\
\text { indivíduo com } \\
\text { "status libertatis, } \\
\text { negativus" em face } \\
\text { do poder estatal. }\end{array}$ & $\begin{array}{l}\text { Agigantamento do } \\
\text { poder estatal, } \\
\text { usurpação de poderes, } \\
\text { resultando na } \\
\text { exploração e } \\
\text { superregulação dos } \\
\text { indivíduos na } \\
\text { sociedade. }\end{array}$ & $\begin{array}{l}\text { Separação de poderes, } \\
\text { direitos constitucionais } \\
\text { contra os poderes, } \\
\text { federalismo, separação } \\
\text { entre religião e Estado. }\end{array}$ & $\begin{array}{l}\text { Montesquieu } \\
\text { John Locke } \\
\text { Immanuel Kant } \\
\text { Federalist Papers }\end{array}$ \\
\hline $\begin{array}{l}3 \text { Democracia: } \\
\text { indivíduos legitimam } \\
\text { o poder por meio do } \\
\text { "status activus". }\end{array}$ & $\begin{array}{l}\text { Agigantamento do } \\
\text { poder estatal, } \\
\text { usurpação de poderes, } \\
\text { resultando numa } \\
\text { incapacitação política. }\end{array}$ & $\begin{array}{l}\text { Direitos de liberdade } \\
\text { de expressão e de } \\
\text { comunicação } \\
\text { (manifestação do } \\
\text { pensamento, reunião, } \\
\text { associação), direito de } \\
\text { voto, direito de } \\
\text { oposição no } \\
\text { parlamento. }\end{array}$ & $\begin{array}{l}\text { Jean-Jaques Rousseau } \\
\text { Immanuel Kant } \\
\text { Federalist Papers }\end{array}$ \\
\hline $\begin{array}{l}4 \text { Estado Social: } \\
\text { indivíduos } \\
\text { subvencionados pelo } \\
\text { Estado em "status } \\
\text { positivus". }\end{array}$ & $\begin{array}{l}\text { Indiferença do governo } \\
\text { com relação às } \\
\text { necessidades da } \\
\text { população, resultando } \\
\text { na pobreza dos fracos } \\
\text { e oprimidos. }\end{array}$ & $\begin{array}{l}\text { Bem-Estar social ou } \\
\text { princípio da justiça } \\
\text { social, incorporação } \\
\text { dos direitos sociais aos } \\
\text { textos das } \\
\text { Constituições. }\end{array}$ & $\begin{array}{l}\text { Lorenz von Stein } \\
\text { Hermann Heller }\end{array}$ \\
\hline $\begin{array}{l}5 \text { Transnacionalidade } \\
\text { I: indivíduos } \\
\text { organizados entre si } \\
\text { no "status } \\
\text { europaeus". }\end{array}$ & $\begin{array}{l}\text { Existência de Estados } \\
\text { Nacionais muito } \\
\text { fortes/fracos na } \\
\text { Europa, indiferença. }\end{array}$ & $\begin{array}{l}\text { Integração dos } \\
\text { Estados Nacionais na } \\
\text { União Européia e } \\
\text { Tratado de Direitos } \\
\text { Humanos da EU. }\end{array}$ & $\begin{array}{l}\text { Winston Churchill } \\
\text { Jean Monnet } \\
\text { Robert Schuman } \\
\text { Walter Hallstein }\end{array}$ \\
\hline $\begin{array}{l}6 \text { Transnacionalidade } \\
\text { II: indivíduos } \\
\text { organizando-se } \\
\text { mundialmente no } \\
\text { "status universalis". }\end{array}$ & $\begin{array}{l}\text { Existência de Estados } \\
\text { Nacionais (e União } \\
\text { Européia) muito } \\
\text { fortes/fracos, } \\
\text { particularismo. }\end{array}$ & $\begin{array}{l}\text { Integração entre } \\
\text { Estados Nacionais e } \\
\text { entre blocos } \\
\text { regionais/continentais } \\
\text { no Direito } \\
\text { Internacional; } \\
\text { invocação de uma } \\
\text { "moral universal". }\end{array}$ & $\begin{array}{l}\text { Immanuel Kant } \\
\text { John Rawls } \\
\text { Jürgen Habermas }\end{array}$ \\
\hline
\end{tabular}

Embora este sumário dos estágios mais importantes do constitucionalismo moderno tenha sido formulado pela primeira vez em 1892, o seu desenvolvimento e 
atualização compreendem a totalidade da história dos riscos e oportunidades representados pelo Estado, não se restringindo ou se aplicando unicamente à Alemanha ou a um determinado país, especificamente. Como será demonstrado, estes estágios de desenvolvimento também se aplicam ao cerne da Constituição brasileira.

1 Status sujbjectionis: conforme foi mencionado, organizar e reconhecer a um Estado poderes soberanos ilimitados (como descrito no quadro acima), produz paz somente em períodos de anarquia e de guerra.

2 Status negativus: uma vez que o problema da anarquia e da guerra está resolvido, exsurgem todos os demais "problemas básicos" atinentes à noção de poder soberano. Um poder político ilimitado pode se sobrepor, explorar e discriminar partes da população - daí por que se faz necessário avançar, na organização estatal, para o estágio seguinte (2). Faz-se necessário incorporar o princípio da liberdade, o que leva aos direitos de defesa, um status em que os cidadãos de um Estado podem autodeterminar-se no sentido de como querem viver suas vidas e desenvolver sua personalidade. Liberdade significa ter a possibilidade de escolher, implicando no direito de escolha em vários dos mais importantes âmbitos da vida: o de escolher uma profissão, um companheiro para casar, um partido político, uma igreja, religião ou associação de sua própria escolha, etc. E escolher com base na liberdade também sempre pressupõe, ainda, mais dois elementos: escolha significa que há várias outras opções (não apenas um parceiro, grupo ou igreja, mas vários); ademais disso, o direito de escolha pressupõe, também, que se tenha o direito de escolher a profissão, o partido, o parceiro, em que acreditar, sem, todavia, se ser compelido a isto. Dito de outro modo, tem-se que todo direito de liberdade possui, ao mesmo tempo, um aspecto ativo e um aspecto passivo. ${ }^{8}$ Daí por que não se concebe como possível um Estado moderno obrigar seus cidadãos a escolherem determinada profissão, igreja, religião ou partido político. Por outro lado, contudo, ele pode esperar que seus cidadãos trabalhem para a sua própria subsistência ou que participem das eleições, caso queira ou considere necessário.

A Constituição brasileira incorpora, por sua vez, todas estas liberdades, ao estabelecer proteção aos direitos fundamentais e também a pluralidade política 
como seus fundamentos (art. $1^{\circ}$, inciso V), bem como garantias e liberdades individuais e coletivas (art. $5^{\circ}$ ), assegurando, da mesma forma, uma série de liberdades específicas, como a de escolha de profissão, de assembléia, de associação, de crença e de expressão (art. $5^{\circ}$, incisos IV, VI, IX, X, XIII, XIV, XV, XVI e XVII, respectivamente), além da pluralidade partidária (art. 15). Todas estas opções de escolha pressupõem, ainda, obviamente, que a vida, a integridade física e a liberdade de locomoção de cada indivíduo também estejam asseguradas - todas elas previstas e contidas, igualmente, no mesmo art. $5^{\circ}$.

3 Status activus: se o direito de representação dos interesses de todos se apresenta como sendo a questão central do constitucionalismo, então a garantia da liberdade política pressupõe mais do que não ser subjugado pelo governo. Isto significa que os próprios órgãos governamentais devem ser estabelecidos com base na livre vontade do povo. Este é o cerne do princípio democrático como elemento de organização do poder interno, sendo suplementado pelo direito de voto de cada cidadão e pela liberdade de manifestação do pensamento, que permitem ao cidadão formar opiniões informadas acerca de como regular as questões públicas. Assim, chegamos ao estágio três de nosso quadro acerca da legitimação da Constituição. ${ }^{9}$

Aqui, novamente a Constituição brasileira segue na direção correta, ao garantir paz e segurança, assim como uma vida digna, para todos: o princípio da democracia (ou da livre vontade do povo) é mencionado várias vezes ao longo do texto (no preâmbulo e no art. $1^{\circ}$ ); além disso, a Constituição assegura o direito de voto universal e secreto (art. 14) e também a liberdade de manifestação do pensamento (art. $5^{\circ}$, inciso IV), bem como o pluralismo e a cidadania (art. $1^{\circ}$, incisos II e V).

4 Status positivus: neste ponto, a justa e legítima representação de cada cidadão de um Estado necessita ser fortificada. Nem todo membro da sociedade é capaz de competir em condições de igualdade e de efetivamente ter uma vida boa. Há jovens e velhos, assim como doentes, por exemplo, fracos demais para competir. Pode, também, haver grupos de pessoas tradicionalmente em desvantagem em suas oportunidades de vida em virtude de sua ascendência étnica, da cor de sua pele ou até mesmo de sua religião. Se estas pessoas tiverem que se submeter e aceitar aquilo que a maioria democrática decide - sem promover revanches ou 
massacres - então a eles deve ser dada uma chance não só de alcançar a representação política, mas também de ter seus interesses financeiros, sociais e culturais considerados e protegidos. Daí por que o estágio quatro integra a maior parte das Constituições, seja explícita ou implicitamente. Ele implica em uma justa distribuição, ou, se necessário, redistribuição dos bens - sociais e naturais - no sentido de proteger os jovens, velhos, fracos e as parcelas desfavorecidas da população. É claro que o princípio do bem-estar social não substitui o dever geral de que cada pessoa deve ser capaz de trabalhar e de cuidar de si ou de sua família. A proteção estatal, aqui, é meramente subsidiária ${ }^{10}$, no sentido de garantir padrões mínimos de existência a todos os indivíduos e grupos.

Mais uma vez, a Constituição brasileira se mostra conectada a esta tendência, ao incluir em seu texto os princípios da justiça social e do bem-estar, assegurandoos a todos e, em especial, às parcelas carentes da população. Ela menciona, reiteradamente, preocupações como "justiça", "bem-estar" e "desenvolvimento social" já no preâmbulo, bem como ao longo de todo o seu texto, quando os coloca como fundamentos e objetivos do Estado (conforme se pode perceber na leitura dos arts. $3^{\circ}$, incisos I, II e III) e também quando elenca um amplo rol de direitos sociais (art. $6^{\circ}$ ), bem como quando condiciona determinados direitos individuais a uma dimensão coletiva, como ocorre no caso da "função social da propriedade" (art. $5^{\circ}$, inciso XXIII), ou no próprio caso da ordem urbana, econômica e social, em que estes aspectos restam claramente destacados. Além disso, ela impõe e obriga os poderes públicos a respeitar e a promover a "justiça social" em diversos momentos - tais como saúde e educação (arts. 170, 193, 196 e 205) - e promove suporte e proteção aos indivíduos e grupos considerados hipossuficientes, tais como crianças, jovens, idosos, mulheres e famílias (arts. 226 e seguintes), consumidores (art. $5^{\circ}$, inciso XXXII) e índios (art. 231).

5-6 Status europaeus e status universalis: a legítima representação dos interesses da população requer, finalmente, neste estágio, uma abertura da estrutura governamental interna ao consenso e ao direito internacional. Por que isto? Não se poderia afirmar, em face da noção de soberania previamente desenvolvida, que um Estado soberano é e deveria ser uma organização separada e independente de tudo o que ocorre em seu entorno? Teoricamente poder-se-ia responder 
afirmativamente a esta questão. Empírica e normativamente, contudo, isto não faz qualquer sentido. Empiricamente, todo e qualquer Estado (seja ele velho ou novo, poderoso ou fraco), em alguma medida, depende de outros países, vizinhos ou não, para a sua segurança, economia e cultura. Esta assertiva se apresenta como verdadeira até mesmo para a superpotência do momento, os Estados Unidos da América, como bem demonstram as conseqüências da guerra do Iraque. Mas também existem questões normativas que apontam para uma necessidade de se observarem e se levarem em consideração os aspectos supranacionais. Se, empiricamente, um país é dependente de outros e se torna mais forte tendo parceiros, então a coordenação de matérias como segurança, economia e comércio requer a conformação de padrões de conduta supranacionais e internacionais. No mesmo sentido, se um país pretende demonstrar à sua população que suas ações são legítimas e merecem ser aceitas pacificamente por todos os destinatários, então a consideração com relação aos padrões das demais comunidades se faz necessária. ${ }^{11}$ Daí porque, após a II Guerra Mundial, uma guerra na qual a Alemanha trouxe dor, sofrimento e injustiça a várias partes do mundo, a Europa e a comunidade mundial se engajaram no desenvolvimento de um amplo regime de tratados internacionais sobre direitos humanos, como forma de se complementarem e fortificarem os direitos constitucionais de ordem interna. A Europa desenvolveu até mesmo uma suplementação institucional com relação aos Estados Nacionais, ao estabelecer a União Européia. Em razão disso, existem, na Europa, além da Constituição interna de cada Estado, mais dois níveis de integração legal: um que corresponde ao estágio cinco (especificamente para direitos e instituições européias) e um que condiz com o estágio seis, para a integração destes Estados e da União Européia na ordem jurídica internacional e nos tratados internacionais sobre direitos humanos. ${ }^{12}$ Posto em termos genéricos, a necessidade de proteção supranacional desses direitos e instituições se deve, por um lado, ao fato de que a experiência histórica demonstra que os Estados Nacionais podem ser demasiadamente autocentrados, egoístas e/ou imperialistas para assegurar uma vida boa aos demais países e a seus cidadãos em sua relação com o resto do mundo. Ou, por outro lado, é possível que determinados Estados Nacionais sejam muito fracos ou pequenos para enfrentar problemas - tais como o desenvolvimento de um meio ambiente saudável e a segurança internacional - que transcendem os limites territoriais. 
A Constituição brasileira, por sua vez, se apresenta como perfeitamente consciente dessas necessidades: ela vincula a política internacional à autodeterminação, mas também à cooperação internacional e à promoção dos direitos humanos e da paz internacional (art. $4^{\circ}$, incisos I a X). E, embora na América não exista uma organização continental tão poderosa quanto a União Européia, ela faz especial menção, no parágrafo único do mesmo art. $4^{\circ}$, ao processo de integração da América Latina, enfatizando o objetivo de se alcançar uma "comunidade de nações latino-americanas" baseada em uma integração econômica, política, social e cultural. ${ }^{13} \mathrm{E}$, com relação à proteção dos direitos individuais, ela os assegura não apenas internamente, no "Bill of Rights" do art. $5^{\circ}$, mas também no nível internacional (art. $4^{\circ}$, inciso II), vinculando todos os poderes estatais não só aos direitos previstos na Constituição, mas também aos conteúdos e liberdades previstos em tratados internacionais sobre direitos humanos de que o Brasil é parte (art. $5^{\circ}$, parágrafo $2^{\circ}$ ), fato reforçado pela previsão de reconhecimento e de submissão ao Tribunal Penal Internacional (art. $5^{\circ}$, parágrafo $4^{\circ}$ ). Assim, ambas as esferas possuem o status de norma constitucional, reforçando a noção de supremacia da Constituição com relação a todas as instâncias governamentais.

\section{LIBERDADE E IGUALDADE}

Antes de tentar resolver alguns problemas práticos referentes à interpretação dos direitos constitucionais, faz-se necessário analisar algumas questões centrais no que concerne aos ideais que norteiam as relações entre cidadãos e governo. Já foi mencionado - notadamente ao tratarmos dos estágios dois e três do esquema evolutivo do constitucionalismo moderno, traçado acima - o papel central representado pela liberdade, concebida numa dupla dimensão: pessoal e política. ${ }^{14}$ Assim, a liberdade implica no direito de escolha em diversas áreas importantes da vida; ela pressupõe, igualmente e ao mesmo tempo, um "elemento ativo", um direito de ação ("liberdade para" ou "liberdade de", como ocorre no direito de associação e de livre manifestação do pensamento, por exemplo) e um "elemento passivo" (direito de ficar calado, direito à privacidade, etc.). Também se poderia localizar este elemento do liberalismo no direito de entrar e de sair livremente das associações (direito que, na Constituição brasileira, aparece previsto no art. $5^{\circ}$, inciso XVII). 0 princípio de liberdade pressupõe, ainda, que haja diferentes opções de escolha, isto 
é, que haja a possibilidade de opção. Dito de outro modo, estas liberdades demandam, para a sua realização, a existência de diversidade e de pluralidade em termos de oportunidade e de identidade em diferentes aspectos. ${ }^{15}$ Neste sentido, diversidade e pluralidade são valores que a Constituição brasileira menciona inúmeras vezes, em diferentes momentos e lugares (art. $1^{\circ}$, incisos III e V; art. $3^{\circ}$, inciso IV; art. 17, dentre outros).

A tabela originalmente formulada por Jellinek, todavia, não menciona especificamente o princípio da igualdade, o que, por sua vez, poderia ser considerada uma séria deficiência do quadro esquemático por ele desenvolvido. Ao se proceder a uma análise mais acurada, entretanto, tem-se que o direito à igualdade pode ser facilmente identificado como abrangido neste contexto, pois a diversidade possui uma estreita vinculação com a igualdade. Se há uma pluralidade de etnias, de religiões e de culturas presente na população de uma país, é preciso que todas elas tenham a mesma consideração e respeito. A Constituição brasileira, por sua vez, pressupõe e incorpora este aspecto, implicitamente, no preâmbulo (ao falar da igualdade e de uma sociedade pluralista) e o estatui, explicitamente, nos arts. $3^{\circ}$, inciso IV e art. $5^{\circ}$, caput. O princípio de igualdade pressupõe, ainda, a descentralização do poder, de modo que as diferentes identidades raciais, étnicas, culturais e religiosas que compõem a sociedade possam ser devidamente consideradas no processo político. Neste ponto, o estágio quatro do quadro esquemático, que prevê o bem-estar e a justiça social, também se afigura como uma corporificação do princípio da igualdade, ao pressupor e assegurar uma igualdade de chances e de oportunidades a todos os indivíduos e grupos, a fim de que todos possam ter, pelo menos, uma vida decente. De acordo com o princípio da igualdade, ainda, o que é igual deve ser tratado de forma igual, e o que é diferente deve ser tratado de forma diferente ${ }^{16}$, ou seja, é preciso que se trate igualmente os iguais e desigualmente os desiguais. Tendo-se em vista o fato de que este tratamento discriminatório em sentido positivo é muitas vezes alvo de contestações, a Constituição brasileira, assim como a maioria das demais Constituições modernas, estabelece alguns critérios e autoriza diferenciações (o próprio art. $5^{\circ}$, inciso I, prevê a igualdade entre homens e mulheres, "nos termos desta Constituição", isto é, prevendo e autorizando, desde já, alguns tratamentos diferenciados, como ocorre no art. $7^{\circ}$, inciso $\mathrm{XX}$, em que se determina a proteção do mercado de trabalho da 
mulher), porém deixa a critério do legislador debater e decidir acerca dessas distinções. Assim, afigura-se como ilegal aquela discriminação em que o governo se baseia exclusivamente em critérios como "raça, cor, sexo, religião, opinião política ou origem ética" (art. $3^{\circ}$, inciso IV) para determinar direitos e obrigações a seus cidadãos. Pode-se perceber, portanto, que a igualdade, enquanto princípio, é composta por diferentes elementos, todos interligados entre si. Dentro deste contexto, a noção que melhor reflete o postulado de "igualdade perante a lei" (art. 5, caput) pode ser traduzida na necessidade de tratamento com igual respeito e consideração (Dworkin) ${ }^{17}$, aspectos que também constituem os requisitos básicos da noção de justiça. Igual respeito, dentro deste contexto, significa respeitar a vida que as pessoas escolhem viver (notadamente no que se refere a questões como sexo, religião, etc.). Já a igual consideração demanda que cada indivíduo ou grupo tenha a possibilidade de competir na sociedade em igualdade de condições, em termos de oportunidade. Aqui é que se pode verificar, claramente, por sua vez, a conexão desse conteúdo com o estágio quatro do diagrama, referido acima.

\section{DIGNIDADE}

Assim como ocorre com a igualdade, a dignidade aparentemente também não se encontra compreendida no quadro esquemático de Jellinek. O constitucionalismo moderno (democrático), contudo, coloca a dignidade no patamar mais alto dos direitos constitucionais. Em face disso, o que, num primeiro momento, aparece como uma inconsistência, pode, num olhar mais acurado, ser perfeitamente explicado. A dignidade serve como referência para todas as Constituições modernas e para todos os instrumentos garantidores dos direitos humanos, sendo os seus elementos principais a liberdade e a igualdade, conforme se viu anteriormente. ${ }^{18} \mathrm{O}$ aspecto de liberdade da dignidade humana abrange, primeiramente, proteção à base vital da vida humana, da vida em si e da integridade física e, complementarmente, a liberdade de escolha relacionada ao desenvolvimento da personalidade. Também se poderia explicar esta faceta da dignidade com base no pensamento do filósofo alemão Immanuel $\mathrm{Kant}^{19}$, que sustentava que o governo nunca pode usar os cidadãos como meros meios para alcançar determinados fins - com base na compreensão de que todo ser humano, independentemente de critérios como sexo, origem ou raça, é um fim em si mesmo. A igualdade complementa a liberdade: como 
todo ser humano deve ter direito à vida e o direito de desenvolver livremente sua personalidade, este direito pertence a todos os seres humanos, indistintamente. A condição política para que se realizem estes elementos de liberdade e de igualdade inerentes à dignidade, por sua vez, é a existência de um auto-governo democrático; apenas por meio da livre escolha dos cidadãos - cada um, individualmente - é possível converter os princípios de liberdade e de igualdade em igualdade política. Desta forma, os dois diagramas utilizados para descrever o cerne do constitucionalismo moderno, em verdade, se complementam e se reforçam entre si.

Além disso, a Constituição brasileira incorpora e reflete amplamente esta concepção da dignidade; ela é mencionada, expressamente, em diversos momentos do texto, como no art. $1^{\circ}$, inciso III e no art. 227, por exemplo. Ele claramente combina a proteção do direito à vida com a proteção da dignidade, sendo um a condição de possibilidade do outro. A Carta garante, ainda, em diferentes momentos, tanto de forma genérica quanto especificamente, a liberdade e a igualdade, aí incluídos os direitos políticos necessários ao exercício da democracia (art. 14). Também o art. 230 ilustra bem esta afirmação, obrigando, por exemplo, o Estado, a família e a sociedade a garantir aos idosos o direito de participar e de promover sua integração social e sua dignidade.

\section{RESPEITANDO E PROMOVENDO OS DIREITOS CONSTITUCIONAIS}

$\mathrm{Na}$ maioria dos Estados ocidentais, a principal função dos direitos humanos e fundamentais é "negativa", o que significa que estes direitos são dirigidos contra eventuais abusos de poder, contra a tirania e contra a soberania absoluta, impondo limites ao poder e aos governos. O fundamento que justifica a adoção de uma tal estratégia reside, por seu turno, na própria experiência histórica, que demonstra que "o poder corrompe" e que "o poder absoluto corrompe absolutamente". Este aspecto encontra-se abarcado nos estágios um e dois do quadro esquemático referente à evolução do Estado moderno, esboçado acima. Como atestam os direitos humanos e fundamentais, estes direitos são, primeiramente, vistos como "direitos de liberdade" ou de liberdade "em face de", especialmente ingerências ou coerções governamentais. Neste aspecto, todas as organizações e divisões do poder estatal, sejam elas horizontais (separação de poderes em Legislativo, Executivo e 
Judiciário), sejam elas verticais (federalismo, diferentes níveis de organização e de vinculação - das esferas transnacionais, passando pela nacional até o âmbito local) servem a um único e mesmo propósito: prevenir a tirania e, ao mesmo tempo, possibilitar a coordenação dos poderes estatais na consecução de propósitos legítimos. Por mais importante que seja esta função, contudo, ela não é - e nem poderia ser - a única, como a evolução do constitucionalismo moderno bem demonstra. Manter o governo afastado das pessoas, estabelecendo-se limites e barreiras jurídicas à sua interferência nos direitos de cada indivíduo não se afigura como suficiente para legitimá-lo; é preciso, ainda, que ele se converta em um instrumento do próprio povo, que seja democrático: um "governo do, pelo e para o povo", conforme prega a máxima imortalizada por Abraham Lincoln. O governo deve, igualmente, garantir direitos aos indivíduos ou grupos fracos, pobres e/ou discriminados. Daí porque muitas Constituições nos países do Leste Europeu e da América Latina desenvolveram funções "positivas" para os direitos humanos e fundamentais, para além dos direitos sociais específicos contidos em seus textos. ${ }^{20}$ Estes direitos, em verdade, continuam sendo "negativos" (isto é, atuam como um contraponto e como limite ao poder estatal); porém agora eles também incorporam uma dimensão "positiva", de modo que cada pessoa ou indivíduo pode pretender ver realizados e fazer uso desses mesmos direitos. ${ }^{21} \mathrm{O}$ direito puramente formal de defesa da propriedade ou de inviolabilidade do domicílio, por exemplo, não tem grande valor para quem não possui uma propriedade ou uma casa. É por isto que, como demonstra o princípio do bem-estar social em um nível estrutural, a função defensiva dos direitos fundamentais deve ser suplementada por uma dimensão "positiva". Na Alemanha, este passo no sentido de se agregar ao aspecto negativo dos direitos de liberdade um aspecto positivo (financeiro, organizacional, estrutural e interpretativo), foi dado pelo Tribunal Constitucional, que "inventou" estas funções adicionais em sua jurisprudência do início dos anos cinqüenta. ${ }^{22}$ Desde então, o "status positivus" de Jellinek pode ser encontrado na Lei Fundamental alemã em dois locais distintos: no amplo espectro de direitos sociais previstos na Constituição e nos aspectos doutrinários desenvolvidos para dar suporte a estes direitos.

Neste ponto, a Constituição brasileira de 1988 é ainda mais atual, mais sensível aos interesses dos fracos e oprimidos. $O$ art. $3^{\circ}$, por exemplo, estabelece como objetivos fundamentais da República a promoção da justiça social e a redução das 
desigualdades sociais e regionais, bem como a promoção e proteção dos direitos humanos e fundamentais. Em face disso, resta claro que o governo e todos os seus órgãos devem respeitar as liberdades de todos os cidadãos, mas, ao mesmo tempo, deve promover a realização desses direitos nos casos em que determinados indivíduos ou grupos não estejam em posição de fazer real uso deles. A Constituição, em sua função "defensiva", na maioria das vezes é clara e juridicamente aplicável - como, por exemplo, a garantia de que toda pessoa tem direito de manifestar sua opinião política. A questão torna-se mais complicada, todavia, quando se trata de preencher a função "positiva" dos direitos e liberdades, pois isto, na maioria das vezes, envolve muitos sujeitos e destinatários, além de implicar em custos, tal como se dá como os subsídios e os benefícios sociais. As Cortes Constitucionais, em regra, deixam o manejamento dessas políticas para o Parlamento, sendo refratárias a este "micromanejamento" de custos e benefícios ${ }^{23}$; a exceção a esta regra geral se daria caso o próprio texto da Constituição estabelecesse, de forma bastante específica, quem ganha quanto e de que, fato que, todavia, na maioria dos casos, não acontece.

\section{O PRINCÍPIO DA PROPORCIONALIDADE}

Um aspecto recorrente no constitucionalismo moderno, até mesmo em virtude dos aspectos de conflito e de necessidade de ponderação entre meios e fins imposta pela realização dos direitos sociais positivos, é o princípio da proporcionalidade ${ }^{24}$, aplicado em casos de restrição de direitos fundamentais, que pressupõe, por sua vez, a observância dos seguintes aspectos: (1) os fins previstos são adequados ao interesse público? (2) Há meios menos restritivos capazes de satisfazer o mesmo interesse público? (3) Há uma relação apropriada, adequada, entre o bem público realizado e a restrição do direito contrário? O que todos estes passos demandam é, em última instância, a realização de um fim/interesse público. ${ }^{25} \mathrm{Em}$ princípio, compete ao legislador decidir qual dos fins (políticos, econômicos e sociais), como e em que medida se pretende alcançá-los. Mas tudo isto deve ser realizado dentro dos limites postos pela Constituição. Isto implica, por sua vez, no fato de que também podem existir fins "ilegítimos", fins estes que o legislador não está autorizado a perseguir, sendo que as Constituições, em regra, dão uma indicação clara do que são esses "fins ilegítimos". Onde a Constituição incorpora o princípio da igualdade e 
estabelece critérios específicos proibindo tratamento discriminatório, por exemplo, a violação desses critérios não pode, em momento algum, constituir um fim legítimo do governo.

Neste ponto, a Constituição brasileira, assim como a maioria das Constituições, não menciona expressamente o princípio da proporcionalidade. Ele é pressuposto, no entanto, com base (1) na supremacia da Constituição e (2) na supremacia do indivíduo em face do poder estatal. Ambos os princípios decorrem da natureza vinculante representada pela Constituição brasileira em relação a todos os poderes estatais (art. $3^{\circ}$ ), bem como da supremacia representada pelos direitos e liberdades fundamentais em face de todas as ações governamentais (art. $5^{\circ}$ ), impondo ao governo ter bons motivos/fundamentos antes de restringir quaisquer direitos e liberdades básicas. Ter "bons motivos" implica, antes de mais nada, (1) respeitar o âmbito de proteção dessas liberdades e garantias e (2) estabelecer cláusulas limitativas em relação à possibilidade de sua restrição. Se limitações podem e são consideradas, então elas devem servir, empiricamente, para a realização do bem comum - um bem comum legítimo - de modo que a restrição do direito individual seja apropriada. Como fins "ilegítimos", a Constituição brasileira estabelece, por exemplo, a discriminação com base nos critérios de raça, cor, sexo, crença religiosa, opinião política e origem étnica (art. $3^{\circ}$, inciso IV). Por mais clara que pareça a aplicação desses requisitos, contudo, é possível que determinadas dificuldades práticas exsurjam por ocasião do processo de interpretação e de aplicação da Constituição. O que estes critérios vedam, por um lado, é a criação de leis ou a prática de atos estatais que tenham como propósito prejudicar uma pessoa ou grupo em razão de algum desses critérios (caso em que cabe à jurisdição perscrutar acerca de um eventual desvio de finalidade posto pela legislação), bem como o favorecimento ou desfavorecimento demasiado de um determinado grupo ou indivíduo, ainda que sua finalidade seja legítima. Cabe à Corte Constitucional, então, decidir acerca dos limites e da razoabilidade/proporcionalidade da discriminação proposta, tarefa que se revela extremamente difícil e complexa, afigurando-se como um dos principais alvos de crítica em relação à atuação da jurisdição constitucional na realização e preservação dos direitos fundamentais e da principiologia da Constituição. 
Em um tal contexto, em que se conclui a linha evolutiva traçada em relação ao papel dos direitos fundamentais no constitucionalismo moderno, resta evidenciada a importância por eles desempenhada na estruturação e na consolidação das conquistas históricas - fato que, conforme demonstrado, revela um elemento comum presente no constitucionalismo ocidental - e, sobretudo, a importância da função de garantia e de proteção desses direitos e garantias, notadamente em âmbitos tão complexos, que ultrapassam os meros limites territoriais para buscar elementos e referências, também, na ordem internacional. Neste ponto, a teoria dos status de Jellinek, com algumas adequações e adaptações, revela-se extremamente atual e importante, podendo ser aplicada, também, à realidade constitucional brasileira.

\section{DIE GRUNDRECHTE IN DEN MODERNEN VERFASSUNGEN: EINE KOMPARATIVE ANALYSE ZWISCHEN DAS DEUTSCHE GRUNDGESETZ, DIE AMERIKANISCHE- UND DIE BRASILIANISCHE VERFASSUNG}

\section{ZUSAMMENFASSUNG}

Mit diesem Aufsatz wird versucht, eine Skizze, die in Jellineks Statuslehre begründet ist, über manche wichtige Ansichten des modernen Konstitutionalismus sowie über die Position von Grundrechten in den modernen Verfassungen, zu treiben. Die Grundrechte sind fest mit Jellineks verschiedenen status verbunden und spielen eine wichtige Rolle in der Evolution der modernen Verfassungen, was man sogleich im deutschen Grundgesetz und auch in der brasilianischen Verfassung 1988 beobachten kann.

Stichworte: Brasilianische Verfassung 1988. Grundgesetz. Grundrechte. Jellineks Statuslehre. Moderner Konstitutionalismus.

\section{NOTAS}

\footnotetext{
${ }^{1}$ Este artigo é resultado de convênio privado de cooperação científica e acadêmica firmado entre os autores, envolvendo a Cátedra de Direito Público e do Estado da Ruprecht-Karls Universität Heidelberg, na Alemanha, e o Grupo de Pesquisa "Jurisdição Constitucional aberta", coordenado pela autora, vinculado ao Programa de Pós-Graduação em Direito - Mestrado da Universidade de Santa Cruz do Sul - UNISC e que conta com o apoio financeiro do CNPq.
} 
2 Professor Titular da disciplina de Direito Público e Filosofia do Direito na Ruprecht-Karls Universität Heidelberg e Fellow no Max-Weber-Kolleg da Universidade de Erfurt, na Alemanha; professor convidado de diversas universidades norte-americanas. Autor de inúmeros livros e artigos científicos, destacando-se, dentre os mais recentes: Liberalismus, Pluralismus, Kommunitarismus (1999); Einführung in das öffentliche Recht der USA (2. ed., 2001); Demokratie, Freiheit, Gleichheit (2002); Freiheit und Sicherheit (2004).

3 Doutora em Direito pela Universidade do Vale do Rio dos Sinos - Unisinos, com pesquisa realizada junto à Ruprecht-Karls Universität Heidelberg, na Alemanha. Pesquisadora conveniada da cátedra de Direito Público e do Estado da Ruprecht-Karls Universität Heidelberg, em parceria com o Prof. Dr. Winfried Brugger. Professora da disciplina de Jurisdição Constitucional do Programa de PósGraduação em Direito - Mestrado e de Direito Constitucional na Graduação em Direito da Universidade de Santa Cruz do Sul - UNISC. Coordenadora do Grupo de Pesquisa "Jurisdição Constitucional aberta", vinculado e financiado pelo CNPq.

${ }^{4} \mathrm{Na}$ Teoria do Estado, a soberania aparece como um dos elementos "essenciais" do Estado, sendo este um conceito típico e identificador da noção de Estado moderno, fundada, historicamente, pela figura do Estado-Nação. Sobre este tema, ver RANDELZHOFER, Albrecht. Staatsgewalt und Souveränität. In: ISENSEE, J.; KIRCHHOF, P. (Hrsg.). Handbuch des Staatsrechts der Bundesrepublik Deutschland. 3. Auflage. Heidelberg: C.F. Müller, 2004; também ZIPPELIUS, Reinhold. Allgemeine Staatslehre. 15. Auflage. München: C.H. Beck, 2007. Sobre as transformações operadas no conceito de soberania ao longo do tempo ver, ainda, a interessante reflexão travada por FERRAJOLI, Luigi. $A$ soberania no mundo moderno. Tradução de Carlo Coccioli e Márcio Lauria Filho. São Paulo: Martins Fontes, 2002.

5 Embora esta questão se afigure, no âmbito da teoria constitucional contemporânea, como polêmica e controvertida - não no que se refere à função da jurisdição no que concerne ao controle de constitucionalidade em si, mas sim no que se refere aos limites desse controle, exsurgindo, daí, teorias como a do self restraint ou as political questions, por exemplo. Cf. LEAL, Mônia Clarissa Hennig. Jurisdição Constitucional aberta: reflexões acerca dos limites e da legitimidade da Jurisdição Constitucional na ordem democrática. Rio de Janeiro: Lumen Juris, 2007.

6 JELLINEK, Georg. System der subjektiven öffentlichen Rechte. 2. durgesehene und vermehrte Auflage. Tübingen: J.C.B. Mohr, 1905. Sobre o pensamento de Jellinek, ver PAULSON, S. L.; SCHULTE, M. (Hrsg.). Georg Jellinek - Beiträge zu Leben und Werk. Tübingen: Mohr Siebeck, 2000; também KERSTEN, Jens. Georg Jellinek und die klassische Staatslehre. Tübingen: Mohr Siebeck, 2000.

7 Sobre a atualização operada com relação à teoria dos status formulada por Jellinek, ver BRUGGER, Winfried. Freiheit und Sicherheit: eine staatstheoretische Skizze mit praktischen Beispielen. Baden-Baden: Nomos, 2004.

8 Sobre a dupla dimensão representada pelos direitos fundamentais - mesmo os tradicionais direitos individuais negativos - ver SARLET, Ingo. A eficácia dos direitos fundamentais. Porto Alegre: Livraria do Advogado, 1998.

${ }^{9}$ É possível dizer que uma ordem jurídica que se caracteriza, precipuamente, pela garantia de direitos fundamentais de defesa e pela correspondente garantia de separação dos poderes, bem como pela proteção dos direitos de participação democrática, ao mesmo tempo em que não reconhece direitos sociais, configura o que se poderia designar como um modelo de Estado Constitucional "formal" ou "mínimo". Este é o modelo adotado nos Estados Unidos, enquanto que a maioria das outras Constituições modernas incorpora direitos e funções mais amplas, especialmente no que se refere a direitos sociais e culturais. Estas Constituições são, freqüentemente, designadas como "materiais" ou como Constituições "valorativas". Um "valor", naturalmente, já deixa claro o modelo de referência adotado. Sobre estes conceitos, ver HÄBERLE, Peter. Verfassungslehre als Kulturwisseschaft. 2. Auflage. Berlin: Duncker und Humblot, 1998. p. 368.

${ }^{10}$ Incorpora-se, aqui, a noção dos direitos sociais, de cunho positivo, próprias do constitucionalismo social. Acerca do tema, ver LEAL, Mônia Clarissa Hennig. A Constituição como princípio: os limites da Jurisdição Constitucional brasileira. São Paulo: Manole, 2003, especialmente o primeiro capítulo, e também SARLET, Ingo Wolfgang. Os Direitos Fundamentais Sociais na Constituição de 1988. In: (org.). O Direito Público em tempos de crise: estudos em homenagem a Ruy Ruben Ruschel. Porto Alegre: Livraria do Advogado, 1999. p. 129-173.

${ }^{11}$ Ponto em que o direito comparado e o direito constitucional comparado, em especial, ganham relevo. Este ramo da ciência permite que um povo e seus governantes visualizem quais soluções foram e são dadas a determinados problemas sociais e políticos em outros países. Neste sentido, se faz adequada a designação, feita por Peter Häberle, que considera o direito constitucional 
comparado como "o quinto método de interpretação". Ver, para tanto, HÄBERLE, Peter. Grundrechtsgeltung und Grundrechtsinterpretation im Verfassungsstaat. Zugleich zur Rechtsvergleichung als "fünfter" Auslegungsmethode. In: Rechtsvergleichung im Kraftfeld des Verfassungsstaates. Berlin: Duncker \& Humblot, 1992. Este método naturalmente não possui uma força vinculante (bindung authority), porém pode desempenhar uma força persuasiva (persuasive authority).

${ }^{12}$ Por isso é que todos os livros e manuais de Direito Constitucional alemães possuem um capítulo sobre Teoria do Estado que se ocupa e versa sobre esta integração. Para tanto, ver, por exemplo, IPSEN, Jörn. Staatsrecht I. 17. Auflage. München: Luchterhand, 2005, onde o parágrafo 3 aborda a questão da União Européia e parágrafo 22, a participação da República Federal nas organizações internacionais. Sobre o desenvolvimento histórico do direito internacional público, ver ZIPPELIUS, Reinhold. Allgemeine Staatslehre. 15. Auflage. München: C.H. Beck, 2007.

${ }^{13}$ Neste sentido, o Mercosul não possui um catálogo ou uma declaração específica de direitos, porém - Brasil é signatário do chamado "Pacto de San José da Costa Rica", estando vinculado à Corte Interamericana de Direitos Humanos. Cf. PIOVESAN, Flavia. Direitos Humanos e o Direito Constitucional Internacional. São Paulo: Max Limonad, 1996.

${ }^{14}$ Para uma análise comparativa em uma perspectiva jurídica acerca da noção de "liberdade", ver BRUGGER, Winfried. Freiheit und Sicherheit: eine staatstheoretische Skizze mit praktischen Beispielen. Baden-Baden: Nomos, 2004.

${ }^{15}$ Neste ponto, a liberdade aparece vinculada à noção de "pluralismo", de pluralidade. Ver, para tanto, BRUGGER, Winfried. Liberalismus, Pluralismus, Kommunitarismus. Studien zur Legitimation des Grundgesetzes. Baden-Baden: Nomos, 1999.

${ }^{16}$ No direito brasileiro, este postulado se traduz na máxima "tratar igualmente os iguais e desigualmente os desiguais", refletindo uma noção de igualdade material. Cf. SILVA, José Afonso da. Curso de Direito Constitucional Positivo. 13. ed. São Paulo: Malheiros, 1997.

${ }^{17}$ Para maiores esclarecimento acerca desta fórmula ver DWORKIN, Ronald. Taking rights seriously. Cambridge, Massachusetts: Harvard University Press, 1977.

${ }^{18} \mathrm{Em}$ razão disso é que a "dignidade" também pode ser "descoberta" na Constituição pela Suprema Corte norte-americana após a II Guerra Mundial, embora o conceito em si sequer apareça expressamente em seu texto. Sobre este aspecto ver BRUGGER, Winfried. Grundrechte und Verfassungsgerichtsbarkeit in den Vereinigten Staaten von Amerika. Tübingen: Mohr Siebeck, 1987.

${ }^{19}$ KANT, Immanuel. Grundlegung zur Metaphysik der Sitten. Hamburg: Meiner, 1957.

${ }^{20}$ Conforme já foi referido em momento anterior do presente artigo, este é o ponto em que a Constituição norte-americana se distancia das muitas outras Constituições modernas: a primeira se restringe a assegurar os aspectos da organização democrática e de limitação do poder, enquanto que estas últimas se caracterizam por avançar nestes aspectos e incorporar novos conteúdos.

${ }^{21} \mathrm{O}$ fundamento filosófico desta concepção pode ser encontrado no pensamento de John Rawls, segundo quem o "direito à liberdade" e o "valor da liberdade" não poderiam ser dissociados de forma absoluta. Ver RAWLS, John. $A$ theory of justice. New York: Ithaca, 1974.

${ }^{22}$ Ver, para tanto, a decisão paradigmática em BVerfGE 7, 198, 204, onde se lê que "os direitos fundamentais visam, sem dúvida alguma, em primeira linha, a garantir a esfera de liberdade do indivíduo em face de violações do poder público; eles são direitos de defesa do cidadão contra o Estado. (...) Igualmente certo é, contudo, que a Lei Fundamental (...), em sua concepção acerca dos direitos fundamentais, também instituiu uma ordem objetiva de valores, o que reforça o aspecto principiológico e a força normativa dos direitos fundamentais." Pode-se ver, assim, claramente, por que se designa a Constituição como uma "Constituição de valores" (Wertverfassung), conforme sustentado em momento anterior do presente trabalho. Sobre as modernas funções objetivas dos direitos fundamentais na ordem constitucional alemã, ver PIEROTH, B.; SCHLINK, B. Grundrechte. Staatsrecht II. 22. Auflage. Heidelberg: C.F. Müller, 2006.

${ }^{23}$ No Brasil, a questão do custo representado pelos direitos positivos ainda é analisado em face da chamada "reserva do possível", condicionando-se e vinculando-se a realização dos mesmos a uma análise da possibilidade financeira do Estado, especialmente no contexto de "crise" vivido pelo Estado Social. Sobre esta temática, ver BOLZAN DE MORAIS, José Luiz. As crises do Estado e da Constituição e a transformação espacial dos Direitos Humanos. Porto Alegre: Livraria do Advogado, 2002.

${ }^{24}$ ALEXY, Robert. Theorie der Grundrechte. Frankfurt a.M.: Suhrkamp, 1994.

${ }^{25}$ Para tanto, ver PIEROTH, B.; SCHLINK, B. Grundrechte. Staatsrecht II. 22. Auflage. Heidelberg: C.F. Müller, 2006. 


\section{REFERÊNCIAS}

ALEXY, Robert. Theorie der Grundrechte. Frankfurt a.M.: Suhrkamp, 1994.

BOLZAN DE MORAIS, José Luiz. As crises do Estado e da Constituição e a transformação espacial dos Direitos Humanos. Porto Alegre: Livraria do Advogado, 2002.

BRUGGER, Winfried. Freiheit und Sicherheit: eine staatstheoretische Skizze mit praktischen Beispielen. Baden-Baden: Nomos, 2004.

. Liberalismus, Pluralismus, Kommunitarismus. Studien zur Legitimation des Grundgesetzes. Baden-Baden: Nomos, 1999.

Grundrechte und Verfassungsgerichtsbarkeit in den Vereinigten Staaten von Amerika. Tübingen: Mohr Siebeck, 1987.

DWORKIN, Ronald. Taking rights seriously. Cambridge, Massachusetts: Harvard University Press, 1977.

FERRAJOLI, Luigi. A soberania no mundo moderno. Tradução de Carlo Coccioli e Márcio Lauria Filho. São Paulo: Martins Fontes, 2002.

HÄBERLE, Peter. Verfassungslehre als Kulturwisseschaft. 2. Auflage. Berlin:

Duncker und Humblot, 1998.

IPSEN, Jörn. Staatsrecht I. 17. Auflage. München: Luchterhand, 2005.

JELLINEK, Georg. System der subjektiven öffentlichen Rechte. 2. durgesehene und vermehrte Auflage. Tübingen: J.C.B. Mohr, 1905.

KANT, Immanuel. Grundlegung zur Metaphysik der Sitten. Hamburg: Meiner, 1957.

KERSTEN, Jens. Georg Jellinek und die klassische Staatslehre. Tübingen: Mohr Siebeck, 2000.

LEAL, Mônia Clarissa Hennig. A Constituição como princípio: os limites da Jurisdição Constitucional brasileira. São Paulo: Manole, 2003.

. Jurisdição Constitucional aberta: reflexões acerca dos limites e da legitimidade da Jurisdição Constitucional na ordem democrática. Rio de Janeiro: Lumen Juris, 2007.

PAULSON, S. L.; SCHULTE, M. (Hrsg.). Georg Jellinek - Beiträge zu Leben und Werk. Tübingen: Mohr Siebeck, 2000. 
PIEROTH, B.; SCHLINK, B. Grundrechte. Staatsrecht II. 22. Auflage. Heidelberg: C.F. Müller, 2006.

PIOVESAN, Flavia. Direitos Humanos e o Direito Constitucional Internacional. São Paulo: Max Limonad, 1996.

RANDELZHOFER, Albrecht. Staatsgewalt und Souveränität. In: ISENSEE, J.; KIRCHHOF, P. (Hrsg.). Handbuch des Staatsrechts der Bundesrepublik Deutschland. 3. Auflage. Heidelberg: C.F. Müller, 2004.

RAWLS, John. A theory of justice. New York: Ithaca,1974.

SARLET, Ingo. A eficácia dos direitos fundamentais. Porto Alegre: Livraria do Advogado, 1998.

Os Direitos Fundamentais Sociais na Constituição de 1988. In: (Org.). 0 Direito Público em tempos de crise: estudos em homenagem a Ruy Ruben Ruschel. Porto Alegre: Livraria do Advogado, 1999. pp. 129-173.

SILVA, José Afonso da. Curso de Direito Constitucional Positivo. 13. ed. São Paulo: Malheiros, 1997.

ZIPPELIUS, Reinhold. Allgemeine Staatslehre. 15. Auflage. München: C.H. Beck, 2007.

Recebido para publicação 10/09/2007

Aceito para publicação 05/10/2007 